\title{
Visual Status of HIV and Non-HIV Infected Children in Relation to Anti-retroviral Drug Use and CD4+ Count in Jos, Plateau State Nigeria
}

\author{
Ajibola Barth Meraiyebu ${ }^{1, ~ *}$, Grace Inga Awilo ${ }^{1}$, Aminyene Essien Meraiyebu ${ }^{2}$, Olanrewaju Olaiya $^{3}$ \\ ${ }^{1}$ Department of Physiology, Bingham University, Karu, Nigeria \\ ${ }^{2}$ Limi Hospital, Abuja, Nigeria \\ ${ }^{3}$ ProHealth International, Abuja, Nigeria
}

Email address:

ajibolaman@yahoo.com (A. B. Meraiyebu)

*Corresponding author

\section{To cite this article:}

Ajibola Barth Meraiyebu, Grace Inga Awilo, Aminyene Essien Meraiyebu, Olanrewaju Olaiya. Visual Status of HIV and Non-HIV Infected Children in Relation to Anti-retroviral Drug Use and CD4+ Count in Jos, Plateau State Nigeria. Advances in Surgical Sciences.

Vol. 8, No. 2, 2020, pp. 19-26. doi: 10.11648/j.ass.20200802.12

Received: September 17, 2019; Accepted: October 22, 2019; Published: September 7, 2020

\begin{abstract}
In immunodeficiency diseases such as Human Immunodeficiency Virus (HIV) infection, various body functions may be affected; visual function could be one of them. In a child, there are predictable adverse outcomes of the disease that bother physical and mental development. This study sought to investigate any potential compromise of visual function amongst HIV-infected children on anti-retroviral drugs known as Highly Active Antiretroviral Therapy (HAART) use by comparing the visual acuity, colour sense and field of vision in infected and non-infected children. One hundred (100) children aged between 5 to 15 years consisting of fifty (50) HIV infected and fifty (50) non-HIV infected were selected through random sampling. Visual acuity test (Snellen's method), colour sense test (Ishihara chart method) and field of vision test (confrontational method) were carried out. Latest Cluster of Differentiation $4(\mathrm{CD} 4+)$ count of the HIV infected subjects also was collected. Statistical analysis was carried out using the Student $T$ Test and ANOVA. The mean visual acuity of Human Immunodeficiency Virus (HIV) infected children was slightly low compared to the negative group (94.2 \pm 4.61 and $96.4 \pm 12.58$ respectively) but was not statistically significant $(p>0.05)$. The mean of Ishihara colour sense test and that of the field of vision test also showed no statistically significant change between infected and non-infected children. Mean CD4+ count of the HIV infected children increased with age and use of anti-retroviral drugs. From 11 to 15 years, percentage defect in visual acuity increased amongst the HIV infected children, compared to the other ages but not statistically significant ( $\mathrm{p}>0.05$ ). It was concluded that visual acuity decreases slightly with improving CD4+ count and increasing age, for HIV positive children on anti-retroviral drugs. These parameters could be observed in subsequent years and subjects monitored for further investigation.
\end{abstract}

Keywords: Human Immunodeficiency Virus (HIV), Highly Active Antiretroviral Therapy (HAART), Visual Acuity Test, Colour Sense Test, Field of Vision, Cluster of Differentiation 4 (CD4+), Anti-retroviral Drugs

\section{Introduction}

Center for Disease Control (CDC) in 1981 reported the first case of HIV/AIDS infection in the world in the United States of America (USA) [1]. This pandemic has taken a toll of the entire human race with diverse economic and social consequences and above all a potential for visual loss and ultimately blindness [2]. At the end of 2012, it was estimated that 2 million children under 15 years old were infected by
HIV in Sub-Saharan Africa, which was almost $62 \%$ of the world total population in this age group [3, 4].

Prior to the introduction of highly reactive retroviral therapy (HAART), it was found that $50-70 \%$ of HIV infected individual developed non-refractive visual problems during the course of their illness [5]. This placed patients with HIV/AIDS in developing nations with poor health care at higher risks of blindness and low vision. During this preHAART era, the commonest cause of visual loss in these 
patients was CMV retinitis, with about 1-2million cases of bilateral vision loss worldwide [5]. However, with the introduction of HAART and its attendant positive effect on immune recovery, other causes of visual loss are increasingly becoming apparent e.g ischemic maculopathy, cataract, Herpes Zoster Ophthalmicus, Herpes simplex retinitis, optic nerve disease, uveitis, refractive errors, glaucoma and diabetic retinopathy [5-8].

Due to the immunodeficiency prevalent in HIV infected individuals, there is an increased risk and predisposition to diseases of which the eye and its neuronal associations is not an exception. This research intends to study and compare visual status of HIV and non-HIV patients and the various mechanisms that could leads to low vision while comparing the outcome in HIV positive children already on antiretroviral and those that are not. In order to optimize the gain of an effective HIV/AIDS control program, this information would be vital.

In West Africa and specifically in Nigeria, data on ocular manifestations of HIV infected children are scarce hence, one of the reasons for this study. In order to be able to boast of a holistic intervention to this pandemic of HIV/AIDS, visual preservation should also be accorded a priority. This study on visual status of HIV infected children is intended to contribute to essential knowledge needed to optimize the care of HIV/AIDS children in this population and to highlight vision as one of the parameters that should be monitored in HIV infected patients, especially children.

Geographical area of study (Jos, Plateau State)

Jos is a city in the Middle Belt region of Nigeria. The city has a population of 900,000 residents based on the 2006 census (Federal Republic of Nigeria: 2006 population census) $[9,12]$. Jos north Local Government Area (LGA) in Plateau state is the local government that constitutes about one-fifth the population of the state and is the most densely populated LGA having a high prevalence rate of HIV/AIDS of about $6.3 \%$.

Table 1: Visual acuity test scores in percentage; $6 / 6=100 \%$, $6 / 9=80 \%, 6 / 18=60 \%$ and $6 / 36=40 \%$, in cases where the visual acuity is not the same for both eyes the average percentage of the two eyes are taken. V Sero-prevalence Sentinel Survey. This and the poor availability of research works on HIV/AIDS in this area is the reason why Jos was chosen as the case study area for my research.

HIV and the eyes

HIV/AIDS affects the eye by making the eye susceptible to infections because HIV causes a breakdown of the body's immune system predisposing various areas to infection including the eyes. People with HIV who maintain good health i.e. normal CD4+ count and minimal viral load are unlikely to have eye problems related to suppressed immune system [5]. Ocular manifestations of HIV infection are common. Approximately $70-80 \%$ of HIV-infected patients will be treated for an HIV-associated eye disorders during the course of their illness [9]. In general, the CD4+ T cells count has been used to predict the onset of certain ocular infections in HIV positive patients. A CD4+ count below 500 cells $/ \mathrm{ml}$ is associated with Karposi sarcoma and Lymphoma, while CD4+ count below 250 cells $/ \mathrm{ml}$ is associated with pneumocytosis and toxiplasmosis. Below 100 cells $/ \mathrm{ml}$ is associated with retinal or conjunctival microvasculopathy, cytomegalovirus (CMV) retinitis, Varicella-zoster virus (VZV) retinitis, HIV encephalopathy etc [10].

However, aside the use of CD4+ counts for predictions of ocular manifestations, some patients with CD4+ count higher than 200cells/ml reportedly taking HAART reported CMV retinitis. This finding seemingly contradicts the previous one and shows that patients after recovery from the reported eye infections tend to have impaired visual status (e.g. poor visual acuity, colour sense etc) [10]. This report led to this research.

\section{Method}

The aim of the study is to compare the visual status of HIV and non-HIV children between the ages of 5-15years in Jos, Plateau State.

1. To test the eye of the subject in processing and interpreting near-distant vision by carrying out Snellen's visual acuity test.

2. To test the functioning of the retina (including cones) of the subjects in colour sense, using the Ishihara colour test charts.

3. To test the normal functioning of the eye and nerve layer of the retina in field of vision of the subject by confrontational method of field of vision eye test.

4. To analyse the results of the most recent CD4 counts of the HIV positive children in comparison with their vision.

We examine the results obtained from selected visual tests (colour sense, field of vision and visual acuity test) carried out on HIV and non-HIV children in Jos, Plateau State. This was done to find out if their anti-retroviral therapy is implicated in low visual status. To also deduce the mechanisms underlying low vision if any, in the HIV infected children: the parts of the eye that are affected and to advice on the visual state of HIV/AIDS children.

The Process involved going to Faith Alive Foundation, Jos Plateau State and Bingham Teaching Hospital, Jos to interact with some of the patients that were attending their routine clinic visits and carry out the selected eye tests for them. A letter of introduction was obtained from Department of Human Physiology of the College of Health Sciences, Bingham University Karu, Nasarawa State, to the abovenamed hospitals in request for consent to have their patients as my research subjects. Ethical approval was granted by the Research and Ethical Approval Committee of Bingham University alongside informed consent letter and questionnaire for review and approval.

Both hospitals have patients booked for their routine clinic visits every day of the week. Selected days were chosen by me to visit each of the hospitals, from 9.00 am to 12.00 noon for a three weeks period until the required number of subjects are reached. The research involved the filling of a questionnaire in order to obtain subjects data such as age, sex 
and HIV status. Medical history (such as how long subject has been on antiretroviral and CD4 count) of HIV the positive children were obtained from the patient's files.

The research involved the investigation of their visual status using visual acuity test (Snellen test), color test (Isihara's chart) and field of vision test (perimetry test) of HIV and non-HIV infected children.

\subsection{Experimental Protocol}

\subsubsection{Visual Acuity (Snellen Chart)}

Good natural light was ensured, to illuminate the patient's face and the charts during the test.

As described by [11].

1. The apparatus for the visual acuity test was set up.

2. The measuring tape was used to measure a point six (6) meters away from the chart.

3. The procedure was explained to the subject and he or she guided to fill out the questionnaire. A clean and dry occluder was handed over to them to be used to cover one eye at a time (Hand could be used but ensure to be clean).

4. The subjects were accepted one at a time for the procedure. While standing at the 6 meters point, one eye was tested at a time (first without spectacles if worn by the subject).

5. Using the occluder the subject was asked to cover one eye without pressing hard against the eye.

6. The subject was then asked to read-out loud the letters on the Snellen chart, from the top of the chart and from the left to the right. If the subject cannot read the letters due to language difficulties, the E chart was used, the subject is asked to show the direction the 'legs' of the $\mathrm{E}$ are facing.

7. The result was expressed in a fraction e.g. 6/18. The upper number refers to the distance the chart is from the patient ( 6 meters) and the lower number (usually written next to the line on the chart) is the distance in meters at which a normal eye is able to read that line of the chart.

8. Incomplete lines were added to the last complete line, e.g. $6 / 12+3$, indicating that the patient read the ' 12 ' line at 6 meters and gained 3 letters on the ' 9 ' line.

9. In cases where the subject could not read the largest (top) letter, him/her was moved closer, 1 meter at a time until top letter can be seen - the VA was then recorded as 5/60, 4/60 etc.

10 . The results were noted down on the questionnaire for each subject and later compiled into the results record book.

\subsubsection{Colour Sense Test (24-plate Ishihara Chart)}

The test was administered under standardized conditions:

1. Room illumination was measured to be 410 lux and a standard test distance of $75 \mathrm{~cm}$ was maintained throughout.

2. The tests were mono-ocular with an interval of 5 minutes.
3. Plates are divided into four designs: demonstration, transformation, vanishing, hidden digits and diagnostic plates.

4. Each subject was to give 30 seconds maximum to identify and call out the number on a plate.

5. After explaining procedure, the 24 plate Ishihara colour test chart was given to the subject.

6. While looking at each page with both eyes, the subject called out the number that he or she could see on the plate or traced a colour pattern with his or her fingers.

7. The result was recorded according to the standard Ishihara test method as stated by Dr. Shinobu Ishihara (1972) [12].

\subsubsection{Field of Vision Test}

Procedure as described by Anderson and collegues in 2008;

1. The subject was made to sit directly opposite the examiner, with their knees almost touching and having their head and eyes on the same horizontal plane.

2. The subject was made to close one eye with his or her hand or an occluder and look straight to the examiner's corresponding eye.

3. The examiner moves his or her fingers in the air from the periphery left and right towards the center, from far above towards the level of the eye and from far below upward which correspond to the four visual quadrants (upper, lower, temporal and nasal).

4. The subject is to notify the examiner when he or she sees the examiners hand and finger movements.

5. The limits of field of vision of the subject at all the regions were then scored by the examiner on the result sheet.

\subsection{Anti-retroviral Drugs Used by the Hospitals}

The HAART which is Highly Active Retroviral Therapy is a highly reactive retroviral therapy.

which is a combination of Nucleoside/nucleotide reverse transcriptase inhibitors (NRTIs) drugs.[13]. Both hospitals used as case study: Faith Alive Foundation and Bingham University Teaching Hospital, the list of most commonly used anti-retroviral drugs include;

1. "Tenovofir"

2. "Combivir"( a combination of lamivudine/zidovudine)

3. "Lamivudine" (Epivir)

4. "Emtricitabine"

5. "Zidovudine" (Retrovil)

6. "Trizivir" (a abacavir/lamivudine/zidovudine)

Each patient was monitored over time to see the improvement or decline with the ARV drug used. Drugs were changed in case of any adverse reaction, accordingly [13].

\subsection{Statistical Analysis}

Statistical analysis was carried out using the student $\mathrm{T}$ test and ANOVA. Mean and standard error of mean (SEM) for the groups. The $\mathrm{T}$ test was carried out with the aid of Statistical Package for Social Sciences (SPSS) software, the 
mean of the groups was determined and the significance of $\mathrm{T}$ value of the groups at $<0.05$ were also determined. Bar charts, graphs and tables were used to represent result data.

\section{Results}

\subsection{Visual Acuity Test Results}

1. In the negative group which had a total of fifty (50) children, forty-five (45) had visual acuity of $6 / 6$ for both left and right eyes (90\%), three (3) had a visual acuity of $9 / 6(6 \%)$ and one (1) had visual acuity of $36 / 6(4 \%)$.
2. In the positive group which consists of fifty (50) children, forty (40) had 'good' visual acuity of $6 / 6$ for both left and right eyes (80\%), six (6) had $9 / 6$ for both eyes which was categorized as 'poor' $(12 \%)$, one (1) had $9 / 6$ visual acuity for the left eye while the right eye was covered by a cataract (2\%), another (1) had visual acuity of $9 / 6$ for one eye but $6 / 6$ (good) for the left $(2 \%)$. Two (2) had 18/6 classified as 'very poor' (4\%) one (1) had $18 / 6$ for the left eye and $6 / 6$ for the right eye. These results are shown in table 1.

Table 1. Summary of result analyses of percentage visual acuity.

\begin{tabular}{lllll}
\hline Groups & Mean \pm SEM & T-value & P-value (>0.05) & Summary \\
\hline Negative group & $94.2 \pm 4.61$ & 0.61 & 1.98 & not significant \\
Positive group & $96.4 \pm 12.58$ & & & " \\
\hline
\end{tabular}

Visual acuity test scores in percentage; $6 / 6=100 \%, 6 / 9=80 \%, 6 / 18=60 \%$ and $6 / 36=40 \%$, in cases where the visual acuity is not the same for both eyes the average percentage of the two eyes are taken.

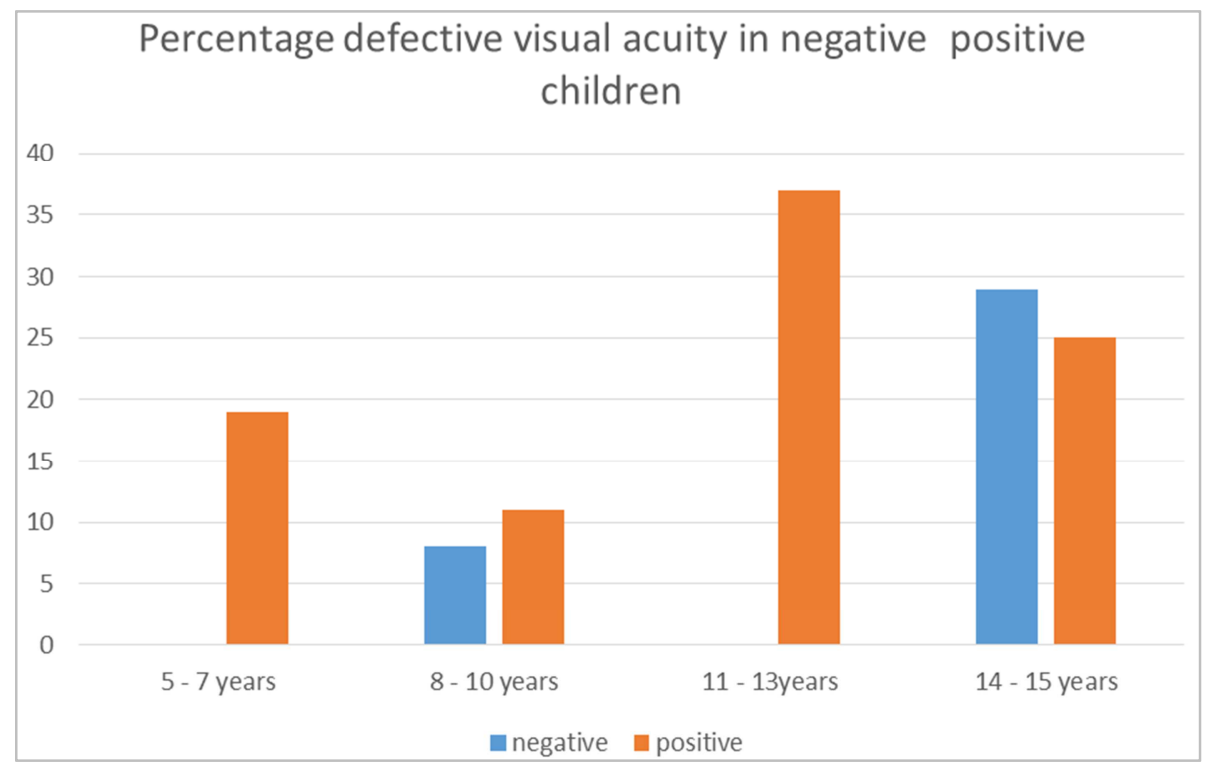

Figure 1. Bar chart showing percentage defect in visual acuity in HIV positive children.

\subsection{Colour Vision Test Results}

1. Dr. Shinobu Ishihara who developed the Ishihara chart in 1972 gave a standard classification of the results into normal, fairly normal and deficient. Score of 23-24 is 'normal', 22-20 is 'fairly normal' and 19 and below is read as 'deficient'. In the control group which consists of fifty (50) children, forty-seven children had an Ishihara test score of 23-24/24 (94\%), one scored 21/24 $(2 \%)$ and two scored 20/24 (4\%). Hence, forty-seven
(47) children had normal colour vision and three (3) fairly normal.

2 . In the test group, forty-eight (48) children scored 23$24 / 24(96 \%)$, one (1) scored 20/24 (2\%) and one (1) scored 19/24 (2\%). Hence, 48 children had normal colour vision and two were fairly normal. This results are shown on Table 2.

3. Colour vision test scores in percentage, $24-23 / 24=100 \%$, $22-21 / 24=80 \%$ and $20-18 / 24=60 \%$.

Table 2. Summary of result analysis for percentage coluor vision test.

\begin{tabular}{lllll}
\hline Groups & Mean \pm SEM & T-value & P-value (>0.05) & Summary \\
\hline Negative group & $98.4 \pm 7.90$ & 1.153 & 1.98 \\
Positive group & $98.0 \pm 8.32$ & & Not significant \\
\hline
\end{tabular}




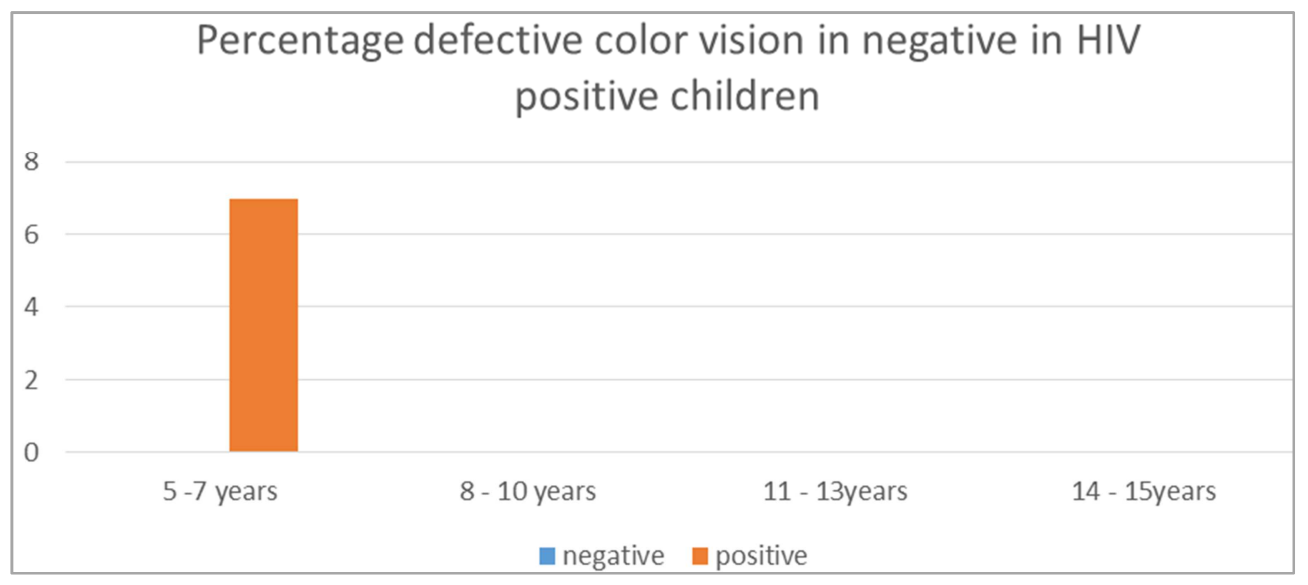

Figure 2. Bar chart showing percentage defective color vision in HIV positive children.

\subsection{Field of Vision}

In the control group, all the fifty (50) children had normal field of vision for frontal, temporal, superior and inferior fields. In the test group of fifty (50), all of them had normal field of vision also.

Table 3: Raw data Represented in percentage, visual acuity, $6 / 6=100 \%, 9 / 6=80 \%, 18 / 6=60 \%$ and $36 / 6=40 \%$. For Colour vision, $24-23 / 24=100 \%, 22-21 / 24=80 \%$ and $20-18 / 24=60 \%$.

Table 3. Data distribution of HIV positive children according to age, CD4 count and visual acuity.

\begin{tabular}{lllll}
\hline Age (years) & Frequency & $\begin{array}{l}\text { \% Defect in visual } \\
\text { acuity (HIV negative) }\end{array}$ & $\begin{array}{l}\text { \% Defect in visual acuity } \\
\text { (HIV positive) }\end{array}$ & Mean visual acuity ( \pm S. E. M) \\
\hline $5-7$ & 16 & 0 & 19 & $95 \pm 133.33$ \\
$8-10$ & 19 & 8 & 11 & $97.9 \pm 39.77$ \\
$11-13$ & 11 & 0 & 37 & $93.6 \pm 165.46$ \\
$14-15$ & 4 & 29 & 25 & $90.0 \pm 133.33$ \\
TOTAL & 50 & & & $576 \pm 59742.78$ \\
\hline
\end{tabular}

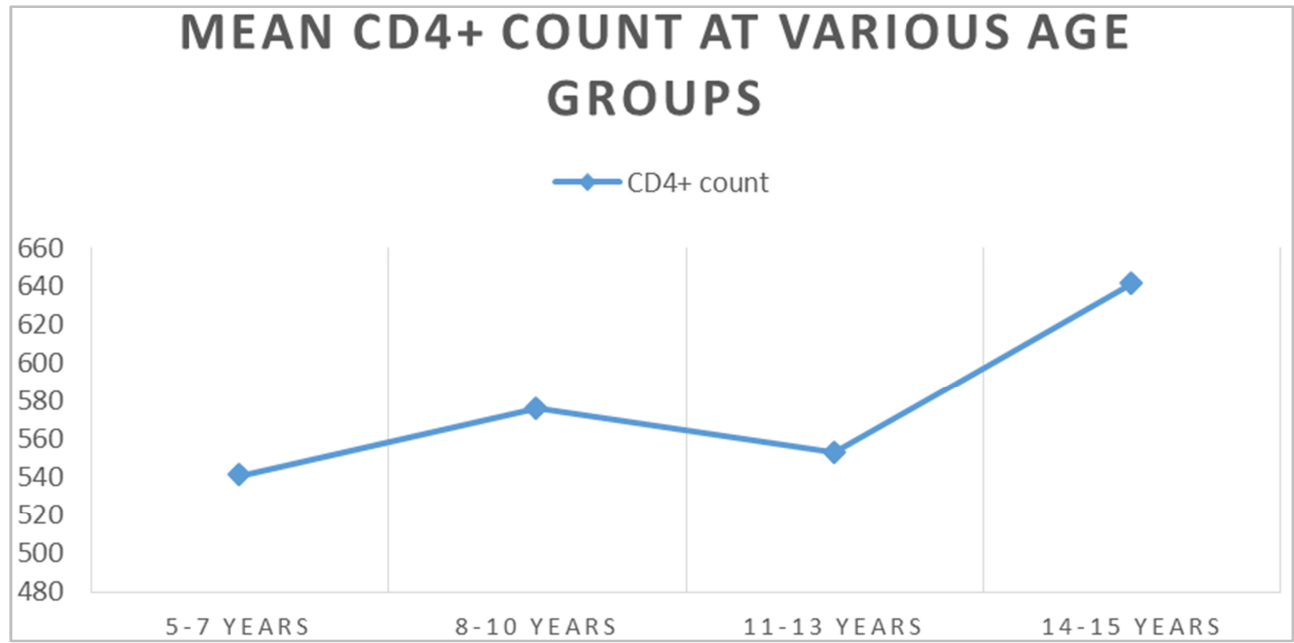

Figure 3. Graph of mean CD4+ count of the various age groups of HIV positive children.

\subsection{Results of Comparison of Means Between Age Groups}

There were changes in visual acuity test results between age groups 5-7years $(91.25 \pm 5.23), 8-10$ years $(95.79 \pm 9.42)$, 11-13years $(89.09 \pm 3.78)$ and 14-15years $(95.0 \pm 8.22)$ which gave a $\mathrm{pV}=0.45$ (using ANOVA method at $\mathrm{p}>0.05$; critical value being 1.98). This change was determined to be statistically not significant. 


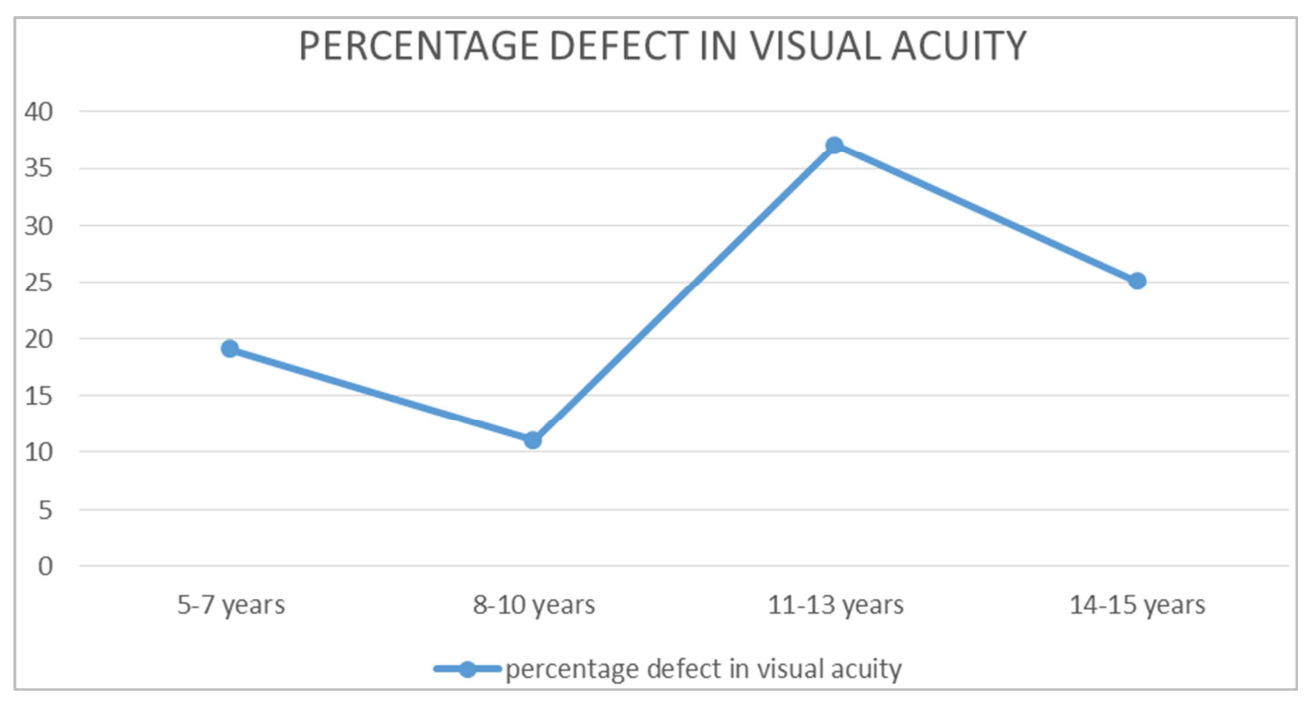

Figure 4. Graph of percentage defect in visual acuity and age groups of HIV positive children.

\section{Discussion}

In the research carried out, the visual status (visual acuity, color vision and field of vision) of both HIV positive and negative children in Jos, Plateau State using subjects from Bingham University Teaching Hospital Pediatric Department and Faith Alive Foundation Hospital Pediatric Department in Jos, Plateau State as case study.

Mean CD4+ count showed increase with increase in age of the HIV positive children (Figure 4). CD4+ count was highest at 14 to 15 years and lowest at 5 to 7 years. This means there is improvement in the population of CD4+ T cells in the blood of the HIV positive children with continuous use of Anti-retroviral drugs as they grow older. HIV causes depletion of the CD4+ T cells thereby weakening the immune system and allowing for opportunistic infections $[14,15]$. that could include any one that affects the visual functions. HIV causes depletion of the CD4+ T cells thereby weakening the immune system and allowing for opportunistic infections $[14,15]$ that could include any one that affects the visual functions.

Mean percentage visual acuity of the HIV positive children (94.2 \pm 4.61$)$ was low compared to that of the HIV negative children $(96.4 \pm 12.58)$ but the difference was not statistically significant at $p>0.05$. The visual acuity test was used to determine the good functioning of the parts of the eyes of the subject involved in processing and interpreting near-distant vision. Percentage defect in visual acuity was higher in HIV positive children within the age of 11 to 13 years which also had a low mean CD4+ count $(553 \pm 25179.10)$ as shown in Figure 1. This suggests possibility that the decreased CD4+ count in the diseased condition which usually brings about accelerated apoptosis of cells (cell death) or systemic inflammation [16] may be the cause of reduced eye function. All these could be the cause a gradual degeneration of visual functions in the eye. Also, continuous infection of the eye with some eye infections commonly found among HIV infected populations such asischemic maculopathy, cataract,
Herpes Zoster Ophthalmicus, Herpes simplex retinitis, optic nerve disease, uveitis, refractive errors, glaucoma and diabetic retinopathy [7]; due to immune-suppression or possible selective viral effect may lead to a decline in visual status of the HIV positive children.

There was also a difference in the mean of colour vision test results of the HIV positive children $(98.4 \pm 7.91)$ when compared to the HIV negative children $(98.0 \pm 8.32)$ but was not statistically significant at $\mathrm{p}>0.05$. However, the percentage defect in colour vision was high within age 5 to 7 years $(8 \%)$ and absent in the other age groups (Figure 2). Since the children have been taking their antiretroviral drugs since from birth, this could be an indication that there was slight colour sense defect at 5 to 7 years, but it corrects out with increase in age and continuous intake of the antiretroviral drugs which based on Figures 2 and 3 improved CD4+ count with increasing age.

For the field of vision tests, there was no difference in the means of the HIV positive and negative groups.

Based on age distribution, the mean visual acuity of HIV infected children between the ages 11 to $13(89.09 \pm 3.78)$ was low compared to the other ages but not statistically significant $(\mathrm{P}>0.05$, critical value 1.98). The percentage defect in visual acuity was higher from age 11 to 15 . This could be an indication that as the children grow older there is possibility of developing poor visual acuity.

In the research carried out, the sex distribution in the HIV positive group was 27 females and 23 males, while the HIV negative group was 31 females and 19 males.

The ages of the HIV positive and negative children were between 5 to 15 years. Mean age of negative group was 10.4 and 9.16 for HIV positive group.

\section{Conclusion}

Visual acuity slightly increased in HIV positive than in the negative group and the minimal colour vision defect which was present in ages 5 to 7 years improved in the subsequent age 
groups. CD4+ count improved with age and continuous administration of respective antiretroviral drugs. Therefore, it was concluded that visual acuity decreases slightly, though not significant with improving CD4+ count and increasing age for HIV positive children on anti-retroviral drugs. The visual status of HIV positive children should be investigated on a larger sample population with increasing age as they advance above 15 years for any form of visual defect, especially in visual acuity.

\section{List of Abbreviations}

$\begin{array}{ll}\text { HIV } & \text { Human Immunodeficiency Virus } \\ \text { HAART } & \text { Highly Active Antiretroviral Therapy } \\ \text { CD4+ } & \text { Cluster of Differentiation 4, } \\ \text { ARD } & \text { Anti-retroviral drugs. } \\ \text { CMV } & \text { Conjunctival microvasculopathy / } \\ & \text { Cytomegalovirus retinitis, } \\ \text { VZV } & \text { Varicella zoster virus retinitis, } \\ \text { NRTIs } & \text { Nucleoside/nucleotide reverse transcriptase } \\ & \text { inhibitors }\end{array}$

\section{Declarations}

\section{Ethics Approval and Consent to Participate}

Ethical approval was granted by the Bingham University Ethical committee and research with Registration Number: BHU/PHYS/R-18-00127-HRC.

\section{Consent for Publication}

Written informed consent was obtained from the participant and their parents for publication of their individual details in this manuscript. The consent form is held by the authors and in the authors' institution, in the patients' clinical notes and is available for review by the Editor-in-Chief."

\section{Availability of Data and Materials}

All data and questionnaires are available on your request.

\section{Competing Interests}

There are no competing interests.

\section{Funding}

Not Applicable.

\section{Authors' Contributions}

Ajibola B Meraiyebu PhD-Manuscript, Experimental Design and Data/Statistical Analysis.

Grace I Awilo BSc-Data Collection, Collation, Statistical Analysis.

Aminyene E Meraiyebu MBBS-Manuscript, Data Analysis, Documentation.

Olanrewaju Olaiya MBBS-Experimental Protocols and Result Collation.

\section{Acknowledgements}

We want to acknowledge staff of Faith Alive Medical Center, Bingham University teaching Hospital and the children and their parents who consented to being used for the research.

\section{References}

[1] Center for Disease Control (CDC). (1981). Pneumocystis Pneumonia-Los Angeles. MMWR Morb Mortal Wkly Rep. 30: $250-252$.

[2] Azonobi I. R and Tebepah T. (2013). Visual status and causes of low vision and blindness among HIV/AIDS patients in Yenegoa, Bayelsa State, Nigeria. J. AIDS Clin. Res. 4: 206. doi: 10.4172/2155-6113.1000206.

[3] Yonaba C, Kalmogho A, Sondo KA, Nacoulma M, Okengo K, Ouedraogo F, Zaoungrana C, Kabore A, Koueta F and Kam L (2016). Ocular manifestations among HIV infected children in Ougadougou, Burkina Faso (PDF). Open Journal of Pediatrics. Vol. 6, page 185-190. http://www.scirp.org/journal/ojped.

[4] UNAIDS (2017). Global summary of the HIV epidemic 2016 (PDF). Retrieved on May 25, 2018 Vitale AT (2005) Global HIV and visual impairment. Cataract and refractive surgery today. Medline Plus.

[5] Kestelyn P. G, Cunningham E. T Jr. (2001). HIV/AIDS and Blindness. Bull World Health Organ. 79: 208-213.

[6] Akduman L, Feiner MA, Olk RJ, Kaplan HJ (1997) Macular Ischemia as a cause of decreased vision in a patient with acquired immune deficiency syndrome Am J Ophthalmol 124: 699-702.

[7] Vrabec TR (2004). Posterior segment manifestations of HIV/AIDS. Surv Ophthalmol, 49: 131-157.

[8] Romano MR, Valldeparas X, Romano F (2006). Bilateral ischemic maculopathy in a patient with AIDS. Eur J Ophthalmol, 16: 761-763.

[9] UNAIDS (2012). The quest for an HIV vaccine. Archived from the original on May $24^{\text {th }} 2012$.

[10] Copeland R. A, Phillpotts A. B and Roy H. (2015). Ophthalmology-Medscape.

https://emedicinemedscape.com/article/1216172-overview.

[11] Marsden J, Stevens S and Ebri A (2014). How to measure distance visual acuity. Community Eye Health Journal, 27 (85): 16.

[12] Matthew RM, Shugaba AI and Ogala WN (2006). Parentsadolescent communication and HIV/AIDS in Jos North Local Government Area, Plateau State, Nigeria. Journal of Medical Sciences, vol. 6: 537, 545. doi: 10.3923/jms.2006.537.545Url.https://scialert.net/abstract/?doi.

[13] Doyle T, Dunn DT, Ceccherini-Silberstein F, De Mendoza C, Garcia F, Smit E, Fearnhill E, Marcelin AG, Martinez-Picado J, Kaiser R, Geretti AM; CORONET Study Group. (2015). Integrase inhibitor (INI) genotypic resistance in treatmentnaïve and raltegravir-experienced patients infected with diverse HIV-1 clades. DOI: 10.1093/jac/dkv243J Antimicrob Chemother. 2015 Nov; 70 (11): 3080-6. doi: 10.1093/jac/dkv243. Epub2015. 
[14] Benneth NJ (2018). HIV infection and AIDS. Medscape; drugs and diseases $>$ infectious diseases. https://emedicine.medscape.com/article/211316-overview.

[15] Pillay D, Genetti AM and Weiss RA (2007). Human immunodeficiency Viruses. In Zuckerman, Arie $\mathrm{J}$ et al. principles and practice of clinical virology (6 $6^{\text {th }}$ ed.) p. 905 . ISBN 978-0-470-51799-4).

[16] Haroun Isah, Elizabeth Isah, Ajibola Meraiyebu, (2017) Lung Function in HIV and Non-HIV Infected Children: FEV1 as a comparative tool. Medical Herald. Vol 4-2017 Pg 28-36. 